\title{
Coronavirus (Covid-19) outbreak on the cruise ship
}

\section{Diamond Princess}

\section{Eilif Dahl}

Department of Occupational Medicine, Norwegian Centre for Maritime and Diving Medicine, Haukeland University Hospital, Bergen, Norway

\section{INTRODUCTION}

The whole world has recently been following the media frenzy covering the quarantine of Diamond Princess, the first cruise ship that had an outbreak of coronavirus illness (Covid-19) on board. It developed soon after the occurrence of China's Covid-19 outbreak, which - according to the World Health Organization (WHO) - "poses a very grave threat for the rest of the world" and should be viewed as "Public Enemy Number 1" [1]. Lasting more than 14 days, the ship quarantine is unprecedented for the cruise industry, and some maritime health issues of concern may be worth addressing already shortly after the interned passengers and crew had finally disembarked the vessel.

\section{THE CRUISE VESSEL OUTBREAK}

Diamond Princess had been on a cruise that originated in Yokohama on 20 January 2020 and included stops in Kagoshima, Hong Kong, Vietnam, Taiwan and Okinawa before returning to Yokohama on 3 February. A passenger, who disembarked on 25 January in Hong Kong, developed a cough on 19 January and on 1 February tested positive for SARS Coronavirus II, a novel virus causing an illness now internationally known as Covid-19. The Japanese government requested that Diamond Princess stay at port in Yokohama, with no passengers or crew disembarking. During 3-4 February, the health status of all passengers and crew was checked by questionnaire by quarantine officers, and respiratory specimens were taken from symptomatic passengers, crew, and their close contacts to test for the coronavirus. On 5 February, a lab-confirmed case of Covid-19 led the Japanese Ministry of Health, Labour and Welfare, to initially quarantine Diamond Princess for 14 days with passengers requested to stay in their cabins. As of 5 February, there were a total of 3711 multinational individuals (2666 passengers and 1045 crewmembers) on board [2].

The primary purpose of vessel quarantine has always been to protect the public ashore by preventing exposure to potentially contagious passengers and crew, regardless of consequences for those aboard. Ships are bound by international treaties to follow port rules and protocols, and in this case Diamond Princess followed the instructions of the Japanese health authorities to the letter while also working closely together with the United States (US) Centers for Disease Control and Prevention (CDC) [3].

Coronavirus virus is thought to spread mainly from person-to-person, between people who are in close contact with one another (within about 6 feet) through respiratory droplets produced when an infected person breathes, coughs or sneezes. It may be possible to get Covid-19 by touching a virus-contaminated surface or object, and transmission might also happen before people show symptoms. Most Covid-19 cases have so far been mild; the overall average mortality rate is estimated at $1-2 \%$, but may change over time [4].

Shortly after quarantine was decided for Diamond Princess, some passengers developed symptoms and tested positive for Covid-19. They were hospitalised ashore while the rest had to remain in their cabins [2].

During the quarantine, the number of persons showing symptoms and testing positive for the virus increased steadily. For a time, the vessel had the largest concentration of cases outside of mainland China, where the virus is thought to have originated [4].

Due to the nature of the ship, individual isolation of all those aboard was not possible. Sharing cabins was necessary, and some crew had to perform essential extra duties while passengers remained aboard. Transmission toward the end of the quarantine period occurred mostly among crew or within passenger cabins [2].

The initial quarantine period was scheduled to end on 19 February. As of 20 February, over 1600 individuals have been disembarked from the Diamond Princess. Nearly all disembarked individuals had observed 14-day quarantine without sharing a cabin with a confirmed case, had received a recent negative polymerase chain reaction tests, and 
had passed a medical screening for symptoms (e.g. fever, cough). At that time 619 cases had been confirmed (16.7\% of the population on board), including 537 passengers and 82 crewmembers. A total of 3011 respiratory specimens had been tested, and 621 were positive (20.6\%), including double tests. Persons aboard between 70 and 89 years of age were the most affected. Of all confirmed cases, 318 (51\%) were asymptomatic when the respiratory specimen was collected (308 passengers and $10 \mathrm{crew}$ ) [2].

On 27 February Princess Cruises confirmed that disembarkation of all guests aboard Diamond Princess had been completed. Of the remaining crew, some departed by foreign government charter flights, while the rest were taken to a local quarantine facility to complete a secondary quarantine required by the Japan Ministry of Health [5].

As of 29 February, Japan's Ministry of Health reported that 705 people from the ship had contracted the virus [2]. CDC announced the same day that 44 passengers flown back to the US had tested positive. At that time 6 people who were on the ship had died in hospitals [3].

\section{QUARANTINE AND CONFINEMENT ISSUES ABOARD}

Cruise vessels are isolated communities with a high population density, crowded public rooms and living accommodation, shared sanitary facilities, and common water and food supplies. Hence, infectious diseases are easily transmitted aboard, by infected persons and through contaminated surfaces, food and water. This also makes handling outbreaks on ships very difficult, in particular the quarantine of large numbers of passengers and crew.

Presence aboard a ship of a newly discovered virus that spreads person-to-person, and possibly via contaminated surfaces and asymptomatic persons, is certainly a challenge, especially when testing possibilities are limited and time-consuming, and getting test results takes days. A Thai physician suggests why early tests on fluids from noses and throats often turns out negative: "The virus lodges deep in the lower windpipe and lungs, so patients will not have a cough or sore throat when they first develop the disease" [6]. Another concern: some Covid-19 patients that seemed cured and tested coronavirus negative, have later had positive tests. This could be due to "reinfection" because of insufficient immune response to the initial infection or "bi-phasic" virus behaviour; the virus lies dormant before creating new symptoms ("reactivation"). Or inconsistent results might be attributed to testing discrepancies.

Adding to the challenge on board Diamond Princess are the facts that initial Covid-19 symptoms are similar to those of influenza and the common cold (fever, cough, respiratory issues), and the Covid-19 outbreaks ashore and then on board started at the height of the annual global influenza epidemics. On a positive note, the risk of confusing influenza symptoms with those of Covid-19 may have been reduced in the crew population because most Diamond Princess crewmembers are annually vaccinated against influenza according to company policy and might already have received this season's dose.

What makes Covid-19 especially problematic for cruise ships, is an incubation time of 2-14 days - and possibly longer, and quarantine of Diamond Princess was therefore necessary for all exposed persons for that long period. Anyone who developed symptoms and tested positive for Covid-19 at any time during their 14-day isolation period may have been contaminated before quarantine started. They then had to be isolated off the ship until they tested negative and could be declared non-contagious. And when new patients were diagnosed, their immediate pre-isolation contacts had to be traced and quarantined as well [2].

In addition to those who got the virus before they were quarantined, further persons on board may test positive for Covid-19 during or after the quarantine period if the cabin seclusion was incomplete, which can easily happen because those in isolation have to be tested, fed and aired mainly by the ship's crew.

\section{CREW EXPERIENCE FROM PREVIOUS OUTBREAKS}

Whether on land or at sea, managerial mistakes will always be made at the start of an outbreak, especially when the illness is caused by hitherto unknown pathogens. Previous outbreak experience helps, and most cruise vessels are quite well prepared to handle smaller outbreak, like those caused by norovirus, the most common cause of acute gastroenteritis outbreaks on cruise ships [7].

A cruise vessel the size of Diamond Princess would normally be expected to have a medical staff of 2 doctors and 3 nurses. That is usually sufficient for daily routine shipboard work, but even a small number of norovirus patients will tax a staff of that size to the limit, even though the average isolation time for such patients is less than two days on a well-run ship.

An outbreak of viral gastroenteritis on a cruise ship, defined as involving more than $3 \%$ of passengers or crew [7], demands the involvement of all officers and crew and will quickly exceed the capacity of the ship's medical staff. Outside assistance will then be essential, but is not always available - for a variety of reasons.

However, an outbreak of a contagious disease where symptomatic patients and their contacts must be isolated for a minimum of 14 days, longer than the length of the average cruise, is truly worrying and brings a multitude of new challenges. The long incubation period alone will drastically influence the practice of cruise ship medicine for the foreseeable future. 


\section{CHALLENGES DURING THE CURRENT OUTBREAK}

The media focus has primarily been on the ordeal of the Diamond Princess passengers, but the controversial 2-week quarantine was even more difficult for the cruise ship's 1045 crewmembers. Cruise vessels are staffed to provide high-level service to their passengers, and the crew is usually kept busy enough by performing their regular duties. During quarantine all kinds of additional services had to be provided - not in public rooms but individually to the passenger cabins, and crewmembers had to do extra tasks, for which they in many cases had not been trained, to keep the quarantined ship running. And they had to do it all while they knew themselves to be at arguably greater risk of getting the illness than the passengers they were serving. They had frequent, although limited, contact with the quarantined passengers, and interacted closely and constantly with other, potentially contagious co-workers during work and off duty, sharing rooms, toilets, and dining spaces. Thus, although effectively protecting the public ashore, quarantine for those aboard was flawed. Consequently, both passengers and crew increasingly felt helpless, anxious, and fearful, and over time various degrees of mental and physical exhaustion were common [8].

A particular quarantine challenge is that Diamond Princess like most cruise vessels has a diverse multinational and multicultural passenger and crew population, with very different service expectations and reactions to authoritarian rules regarding behaviour. After all, people were virtually incarcerated for more than 14 days; in many instances with other persons they wouldn't usually spend so much time with in one small room on a daily basis; the lucky ones had balconies, but many passengers and most of the crew had indoor windowless cabins.

Quarantine is a logistic nightmare for shore-side and ship management and for supervisors at all levels aboard. They must ensure consistently safe and professional operation of all aspects of the vessel, $24 / 7$, also under extraordinary circumstances. Therefore, a primary goal and ongoing challenge will be to keep up morale and motivate a steadily more overtaxed crew to continue not only to work but also to provide the expected "excellent cruise service". There is furthermore constant pressure from the cruise company, port and health authorities, and media for continuously updated documentation of all aspects of their actions. Moreover, unprecedented operations have to be organised: enhanced safety and security measures, special daily housekeeping activities, mobile food and beverage services to all cabins under 'biohazard' conditions, daily strictly supervised walks on deck for passengers with interior windowless cabins, prompt and decisive handling of accidental and planned breeches of confinement, and so on and on.

\section{MEDICAL STAFF CHALLENGES}

The highest-risk group aboard for contracting Covid-19, the ship's few doctors and nurses faced medical and mental health burdens of their own. They must try to handle non-Covid-19 emergencies and regular medical issues of passengers and crew as they usually do, but confined persons are not allowed to visit the Medical Facilities so consultations must be done in the cabin, with limited diagnostic possibilities. Also, the obligatory clinical evaluation and testing of all the potentially infected persons must be done in the cabins as well; just try to imagine the time and effort - and man power - it will take to just make brief individual visits to thousands of people in their living quarters aboard - while ensuring that the contagion is not transferred from cabin to cabin and while trying not to get contaminated yourself.

All the issues addressed above meant additional work for the vessel's medical staff. In such situations they must somehow get prompt medical and other support from ashore, to be arranged through the company's medical headquarter ashore. The Medical Department of Princess Cruises has for many years been in the lead of providing firstrate medical care for passengers and crew and, being part of a large corporation, have the expertise and resources that smaller cruise lines do not command. But support provided from the outside will often be from persons who, unfamiliar with conditions on board, will themselves require help from the already overworked ship staff. For the quarantine-related tasks the ship's medical staff received unspecified assistance from outside, and as of 28 February, one quarantine officer who worked on the ship had contracted the virus [2].

\section{LESSONS LEARNED?}

Retrospectively, it is easy to criticise how the quarantine was handled. Again, the primary quarantine goal for the Japanese port authorities was to protect the public ashore, but trying to keep passengers apart from each other and from crew by retaining them in their cabins was not an ideal solution because potentially contagious crew had to interact among themselves and serve the passengers to keep the ship operation running. Failing to isolate the crew of the Diamond Princess from the beginning of the quarantine likely contributed to further virus transmission to passengers and crew during the quarantine time and made it necessary to subject the remaining crewmembers to another full quarantine period ashore after all passengers had debarked [2].

The Covid-19 quarantine might have serious adverse effects. There will be expert medical and psychological care of all the involved crewmembers during on-going seclusion [5] - and hopefully also long-term follow-up at home. This will be necessary to counteract post-traumatic stress reactions from involuntary frontline work in a dangerous environment - and from the subsequent quarantine ashore. 
Dealing with quarantine of a foreign-flagged and -operated ship is difficult for a single government, and there is clearly a need for a worldwide framework to tackle future crises. Hence, the cruise industry, governments, international maritime organisations, and other stakeholders should push for global treaties to ensure that ports cannot turn away ships with outbreaks but must arrange for urgent quarantine of all potentially contaminated persons not aboard but ashore, as well as for urgent shore-side isolation and hospitalisation of all suspected and symptomatic patients.

Diamond Princess during the first months of 2020 is to be considered a de facto epidemiological laboratory. Evidence gathered from its outbreak will provide important information for the global Covid-19 investigation and must be shared fully to promote future contingency plans and to improve health conditions on all cruise vessels. When (not if) further Covid-19 and similar outbreaks on ships occur, detailed industry plans for worldwide cooperation regarding emergency medical staffing and assistance need to be in place.

\section{FUTURE CRUISING}

High risk of contracting a contagious illness with an incubation time $>14$ days, transmittable through contagious asymptomatic persons and possibly via contaminated surfaces, will change the practice of cruise ship medicine as we know it. Fear of contracting Covid-19 will prevent many prospective customers from booking cruises, in particular itineraries that might include future endemic areas. But before long, a bigger passenger and prospective crewmember concern will be the risk of involuntary quarantine for weeks to months aboard or/and abroad - far away from home.

Eventually, especially when an effective vaccine has become available, conditions may normalize to the extent that Covid-19 will not appear more frightening than influenza. Then the focus will shift to maintaining normal shipboard life as much as possible, whilst implementing standard outbreak prevention measures to reduce the risk of transmission, like less touching and lots of hand washing.

\section{ADDENDUM}

To watch a video where Dr. Grant Tarling, MD, MPH, Chief Medical Officer for Princess Cruises, explains the issues to guests aboard the Diamond Princess on 12 February 2020, please see https://www.youtube.com/watch?v=PGQZjkFg$8 Z M \& t=55 \mathrm{~s}$. The published commentaries are mostly complementary, while the more critical ones demonstrate clearly how little the public at large understands of shipboard life.

\section{CONFLICT OF INTEREST}

The author has no commercial, financial or other relationships related to the subject of this article. He has worked as ship's doctor for many cruise companies, including once for Princess Cruises (Star Princess 2013).

\section{REFERENCES}

1. Nebehay S, Farge E. Update 3- Coronavirus emergency is "Public Enemy Number 1". WHO via Reuter, 11 February 2020. https:// www.reuters.com/article/us-china-health-who/coronavirus-emergency-is-public-enemy-number-1-who-idUSKBN2050YV.

2. The Japanese National Institute of Infectious Diseases (NIID). Field Brief: Diamond Princess COVID-19 Cases. 20 Feb Update. https:// www.niid.go.jp/niid/en/2019-ncov-e/9407-covid-dp-fe-01.html (Accessed 01 March 2020).

3. US Centers for Disease Control and Prevention (CDC). Coronavirus disease 2019. https://www.cdc.gov/coronavirus/2019-ncov/ index.html (Accessed 02 March 2020).

4. Virus monitor. Covid-19 coronavirus outbreak. https://www.worldometers.info/coronavirus (Accessed 29 February 2020).

5. Princess Cruises. Updates on Diamond Princess: Guest Disembarkation Complete + Team Member Quarantine - 27 February 2020. https://www.princess.com/news/notices_and_advisories/notices/diamond-princess-update.htm (Accessed 02 March 2020).

6. Hemachuda T. In: Probe into virus death. Bangkok Post. 2020; 02 March.

7. US Centers for Disease Control and Prevention (CDC). Vessel Sanitation Program 2018 Operations Manual. https://www.cdc.gov/ nceh/vsp/docs/vsp_operations_manual_2018-508.pdf.

8. Subramanian S. The Ordeal of the Diamond Princess Crew. The Diplomat, 22 February 2020. https://thediplomat.com/2020/02/the -ordeal-of-the-diamond-princess-crew (Accessed 01 March 2020). 